\title{
Using Thiazides when Hypertension is Coupled with Immunoglobulin Deficiency
}

\author{
Michael Saul Lundin*, Varun Avula DO and Ramesh Avula \\ Michigan State university, West Bloomfield, Michigan

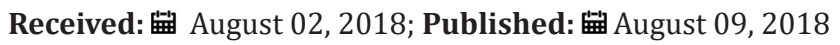 \\ *Corresponding author: Michael Saul Lundin, Michigan State university, West Bloomfield, Michigan
}

\begin{abstract}
Pooled immunoglobulin (Ig) is a scarce and expensive resource, hypertension is the leading cause of death worldwide (as of 2010) [1] as the new blood pressure guidelines in 2017 make note of [2], and there is something that can be done to address both. In this article, we summarize the salient developments in the treatment of hypertension as well as put forward the hypothesis that employing thiazides in patients on chronic Ig replacement therapy may provide the dual benefit of treating blood pressure as well as increasing plasma concentration of immunoglobulins. Furthermore, there may be a side benefit to public health by increasing the supply of pooled immunoglobulin.
\end{abstract}

Keywords: Blood Pressure; Intervention; Salient Developments; Pooled Immunoglobulin; Systolic; Cardiovascular; Diabetes Mellitus; Chronic Kidney Disease; Thiazides; Diastolic; Hypertension

\section{Introduction}

According to the 2017 hypertension guidelines from the American Heart Association as well as a broad consensus of ten other organizations, hypertension is now defined as a blood pressure of greater than or equal to $130 \mathrm{~mm} \mathrm{Hg}$ systolic or $80 \mathrm{~mm}$ Hg diastolic $[1,2]$. This threshold is lower than in JNC 8. As a result, the number of Americans who are now considered hypertensive is $46 \%$ while among elderly Americans, the figure is greater than $2 / 3$. Furthermore, there are a series of well-known trials in internist circles called the Systolic Blood Pressure Intervention (SPRINT) trial which showed the benefits of even more intensive blood pressure control in certain demographics which constitute a very wide swathe of patients. SPRINT showed that among patients at high risk for cardiovascular events, "targeting a systolic blood pressure of less than $120 \mathrm{~mm} \mathrm{Hg}$, as compared with less than $140 \mathrm{~mm} \mathrm{Hg}$, resulted in lower rates of fatal and nonfatal major cardiovascular events and death from any cause" [3].

Individuals with increased risk for cardiovascular events included those with current coronary artery disease or a high risk of developing it, current chronic kidney disease (note that over a third of elderly people have CKD) [4], and even those who had an age of 75-year-old or above (among those who were ambulatory and non-institutionalized) [5]. An analysis of the secondary analysis on the previously done ACCORD trial focused on diabetics and similarly showed the benefits of intensive blood pressure control (blood pressure target of $<120 \mathrm{~mm} \mathrm{Hg}$ as opposed to $<140 \mathrm{~mm} \mathrm{Hg}$ ) with a decrease of major cardiovascular disease outcomes of $26 \%$ [6]. Existing trials lack full generalizability
(SPRINT did not include diabetics, people with prior stroke, or people under the age of 50 years-old) and ACCORD was rather small at only half the size of SPRINT, but to summarize the gist of recent evidence, one should achieve a blood pressure as low as possible in ambulatory, noninstitutionalized patients as long as the patient is not experiencing adverse effects. If there is one sentence to memorize and take home from this whole paragraph, it is: the old blood pressure threshold of $\geq 140$ systolic or $\geq 90 \mathrm{~mm} \mathrm{Hg}$ diastolic is now defined as Stage 2 hypertension [2].

\section{Discussion}

The 2017 blood pressure guidelines are easy to memorize with little subtly. The target blood pressure for patients with hypertension and any of the following conditions is simply 130/80 mm Hg across the board: stable ischemic heart disease, noninstitutionalized ambulatory adults over the age of 65 , peripheral arterial disease, diabetes mellitus, chronic kidney disease. Thiazides (and thiazidelike diuretics) are first-line medications to treat hypertension. Thiazides perform diuresis by blocking the $\mathrm{Na}+-\mathrm{Cl}$ - symporter in the distal convoluted tubule of the nephron. Studies which measured intravascular volume through the use of radiolabeled albumin demonstrated that thiazides decrease intravascular volume persistently. For example, in one of these studies, investigators discontinued thiazides in 8 patients who had been on thiazide therapy (seven patients had been on $25 \mathrm{mg}$ of hydrochlorothiazide twice daily and one patient on chlorthalidone $100 \mathrm{mg}$ daily) for at least six months. 
The investigators found that thiazide therapy chronically decreased intravascular volume by a mean over all the patients of $298 \mathrm{~mL}$ (a $10.4 \%$ decrease) [7]. Other studies have confirmed this [8]. It follows that if the plasma volume is $10.4 \%$ less, this will increase the concentration of administered serum immunoglobulins. One concern that a clinician may have is the use of thiazides causing increased adverse reactions due to hyper viscosity. We feel that this is unlikely. As it is, adverse reactions are quite uncommon in those patients receiving IVIG at a low dose (that is, for the purpose of Ig replacement) on a regular basis. For example, one study of 119 patients receiving self-infusions at home over a year's time (2031 infusions total) reported adverse reactions happening in $0.7 \%$ of infusions [9]. A larger follow-up study of 459 patients receiving infusions at 12 different immunology centers over two years $(13,508$ infusions total) had an adverse reaction rate of $0.8 \%$ of infusions [10]. Neither of these studies had a single serious reaction.

Furthermore, there is no evidence we are aware of that thiazides would increase the incidence of adverse effects in longterm immunoglobulin, nor do we see any pathophysiologic basis for that either. Also, even should a clinician be concerned about the $300 \mathrm{~mL} / 10 \%$ decrease in intravascular volume leading to hyper viscosity at the time of the infusion, this could be easily ameliorated with pretreatment of a $500 \mathrm{~mL}$ bolus of crystalloid. The immunologist could add a thiazide or suggest a patient discuss the matter with his internist. Thiazides are first-line antihypertensives and can easily be added to the current medication regimens with minimal cost or inconvenience to the patient. As an example, one of the authors admitted a male patient who presented to the hospital with urinary tract infection as well as long-standing hypertension. The author discharged the patient the following day, prescribing the patient an amlodipine-valsartan combination pill which is generic and cost the patient only $\$ 10$. At follow-up in the clinic, the patient still had a blood pressure or $150 / 90 \mathrm{~mm} \mathrm{Hg}$, so the clinician added hydrochlorothiazide to the combination pill which now consisted of amlodipine-valsartan-hydrochlorothiazide. This case demonstrates the easiness of adding thiazide therapy.

\section{Conclusion}

Given the very high prevalence of hypertension with new consensus guidelines lowering the definition of hypertension to a threshold of $\geq 130 / 80 \mathrm{~mm} \mathrm{Hg}$, the use of thiazides in patients on immunoglobulin replacement therapy will likely increase the supply of Ig and reduce costs (besides provide benefit by further controlling hypertension).

\section{References}

1. Lim SS, Vos T, Flaxman AD, Danaei G, Shibuya K, et al. (2012) A comparative risk assessment of burden of disease and injury attributable to 67 risk factors and risk factor clusters in 21 regions, 1990-2010: a systematic analysis for the Global Burden of Disease Study 2010. Lancet (London, England) 380(9859): 2224-2260.

2. Whelton PK, Carey RM, Aronow WS, Casey DE, Collins KJ, et al. (2018) 2017 ACC/AHA/AAPA/ABC/ACPM/AGS/APhA/ASH/ASPC/NMA/PCNA Guideline for the Prevention, Detection, Evaluation, and Management of High Blood Pressure in Adults: A Report of the American College of Cardiology/American Heart Association Task Force on Clinical Practice Guidelines. Journal of the American College of Cardiology 71(19): 12691324.

3. Wright JT, Williamson JD, Whelton PK, Snyder JK, Sink KM, et al. (2015) A Randomized Trial of Intensive versus Standard Blood-Pressure Control. The New England journal of medicine 373(22): 2103-2116.

4. Levey AS, de Jong PE, Coresh J, El Nahas M, Astor BC, et al. (2011) The definition, classification, and prognosis of chronic kidney disease: a KDIGO Controversies Conference report. Kidney international 80(1): 17-28.

5. Williamson JD, Supiano MA, Applegate WB, Berlowitz DR, Campbell $\mathrm{RC}$, et al. (2016) Intensive vs Standard Blood Pressure Control and Cardiovascular Disease Outcomes in Adults Aged >/=75 Years: A Randomized Clinical Trial. Jama 315(24): 2673-2682.

6. Margolis KL, O Connor PJ, Morgan TM, Buse JB, Cohen RM, et al. (2014) Outcomes of Combined Cardiovascular Risk Factor Management Strategies in Type 2 Diabetes: The ACCORD Randomized Trial. Diabetes Care 37(6): 1721-1728.

7. Tarazi RC, Dustan HP, Frohlich ED (1970) Long-Term Thiazide Therapy in Essential Hypertension. Circulation 41(4): 709-717.

8. Hansen J (1968) Hydrochlorothiazide in the treatment of hypertension. The effects on blood volume, exchangeable sodium and blood pressure. Acta medica Scandinavica 183(4): 317-321.

9. Brennan VM, Cochrane S, Fletcher C, Hendy D, Powell P (1995) Surveillance of adverse reactions in patients self-infusing intravenous immunoglobulin at home. Journal of clinical immunology 15(2): 116119.

10. Brennan VM, SalomÉ Bentley NJ, Chapel HM (2003) Prospective audit of adverse reactions occurring in 459 primary antibody deficient patients receiving intravenous immunoglobulin. Clinical and Experimental Immunology 133(2): 247-2 51.

\section{ISSN: 2574-1241}

DOI: 10.26717/BJSTR.2018.07.001549

Michael Saul Lundin. Biomed J Sci \& Tech Res

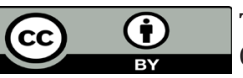

This work is licensed under Creative Commons Attribution 4.0 License

Submission Link: https://biomedres.us/submit-manuscript.php

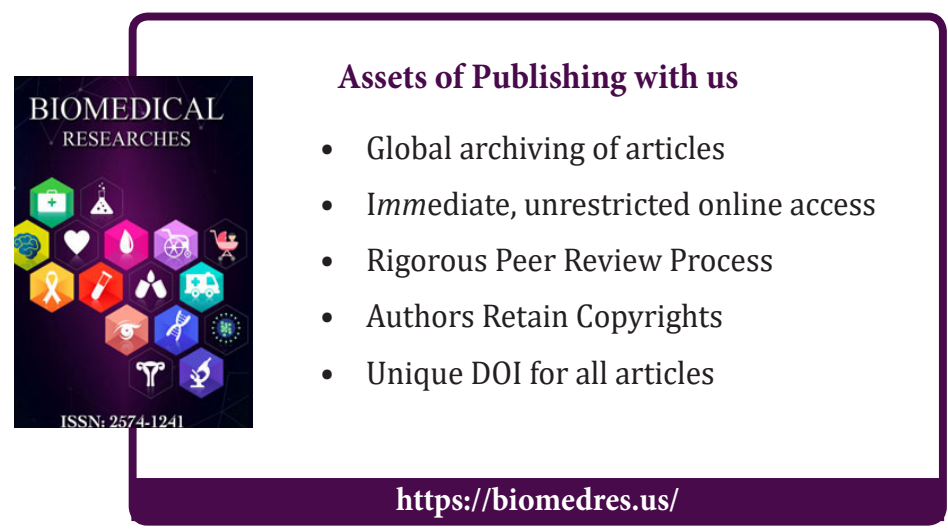

